\title{
Sensitivity Analysis of Impact Velocity and Added Mass for Iceberg/Bergy-Bit Impact with Fixed Offshore Structure
}

\author{
Tanvir Sayeed ${ }^{1}$, Faisal Althobiani² \\ ${ }^{1}$ Memorial University, St. John's, Canada \\ ${ }^{2}$ Faculty of Maritime Studies, King Abdulaziz University, Jeddah, KSA \\ Email: dr.althobiani@gmail.com
}

How to cite this paper: Sayeed, T. and Althobiani, F. (2019) Sensitivity Analysis of Impact Velocity and Added Mass for Iceberg/Bergy-Bit Impact with Fixed Offshore Structure. Open Access Library Journal, 6: e5470.

https://doi.org/10.4236/oalib.1105470

Received: May 14, 2019

Accepted: June 25, 2019

Published: June 28, 2019

Copyright (๑) 2019 by author(s) and Open Access Library Inc.

This work is licensed under the Creative Commons Attribution International License (CC BY 4.0).

http://creativecommons.org/licenses/by/4.0/

\begin{abstract}
Iceberg/Bergy-bit impact with ships and offshore structures is an important consideration to govern design load in ice covered regions. Uncertainty in estimating impact load lies due to size and shape of the iceberg, ice properties and associated environmental effects. Moreover hydrodynamic interaction in close proximity also influences the impact load to a great extent which is still uncertain. Various full scale impact tests showed lower ice loads than would be expected with existing knowledge base. Model scale experiments also have shown different phenomena such as negative wave drift force, fluid cushioning, shadowing, reduction in impact velocity, and hydrodynamic damping. Impact velocity and added mass are two important parameters which influence the hydrodynamic interaction in close vicinity. A simplified iceberg impact model has been developed based on limited energy method and the effects of impact velocity and added mass are identified through sensitivity analysis using Monte-Carlo simulation. The results show significant effects of impact velocity and added mass on maximum impact load estimation which is more pronounced for impact velocity. A realistic impact scenario is demonstrated considering combined effects of increase in added mass and reduction in impact velocity. Statistical Design of Experiments (DOE) is also applied to a bergy bit impact study which reveals the sensitivity of the significant control parameters and their interaction effects on the response. DOE analysis reveals that ice crushing strength is another significant factor besides impact velocity and added mass coefficient that contributes to the maximum impact load estimation.
\end{abstract}

\section{Subject Areas}

Mechanical Engineering 


\section{Keywords}

Impact Velocity, Added Mass, Sensitivity, Iceberg Impact, Monte-Carlo Simulation, Design of Experiment

\section{Introduction}

Estimation of iceberg impact load with ships and offshore structure is an important design consideration. The design load will also vary with type of structure and fixed structures will require more integrity because of lack of capability to move off station. Few full scale iceberg impact tests were conducted by towing icebergs in instrumented pressure panels, for example, field program in Antarctica in 1990 [1], experiments conducted in Newman's Cove in 1992 [2], and Grappling Island tests in 1995 [3]. All these tests showed considerable lower pressure than would be predicted by existing knowledge base. Close vicinity hydrodynamic interaction might be a possible cause for such reduction in loads.

Various model tests also showed considerable uncertainty in near field ice mass interaction with offshore structure. Salvalaggio and Rojansky [4] observed different phenomena depending on size of iceberg under wave action. No impact, slower eccentric impact, stopping just before structure are among those observations. Isaacson and McTaggart [5] also observed negative wave drift causing smaller ice masses (iceberg diameter approximately less than half of structure diameter) either significant reduction in impact velocity or no impact at all. Isaacson and Cheung [6] also identified increase in added mass as the ice mass gets closer to the structure. Colbourne et al. [7] observed reflected wave effects on iceberg and bergy bit during collision with Terra Nova FPSO. Gagnon [8] also indicated proximity effect in between floating ice masses with a tanker passing at speed. Sayeed et al. [9] observed reduction in impact velocity of ice mass just before collision. This effect is more pronounced when the berg size gets smaller and separation distance gets closer.

It is apparent that near field hydrodynamic interaction just before impact is an important consideration to estimate impact loads. Overestimation might result without accounting for hydrodynamic interaction in close proximity. Impact velocity and added mass are two important parameters that will govern this hydrodynamic interaction. The strain rate and failure mode of ice (ductile, transition or brittle) will also be different depending on loading rate ([10] [11]). Usual practice is to take mean open water drift velocity as impact velocity or some researchers took the scalar sum of significant wave induced velocity and drift velocity to account for impact velocity [12]. Rather significant reduction than open water drift velocity just prior to impact was observed by others ([5] [7] [9] etc.). Besides impact velocity, added mass is another uncertain factor and researchers have used added mass coefficients ranging from 0.5 to 1.8. Gershunov [13] emphasized the uncertainty of added mass coefficient and used a range of values 
from 1.2 to 1.8 in his analysis. Chwang [14] claimed change in added mass with change in relative position of iceberg with respect to offshore structure for central, oblique and rotational impacts. Similar conclusions were drawn by several researchers like Cheung [15] and Isaacson and Cheung [6]. That's why impact velocity and added mass are considered important parameters influencing close proximity hydrodynamic interaction.

Sensitivity analysis is a popular method in uncertainty analysis to identify how changes in input values change the output values. Bass et al. [16] identified effects of different factors such as impact velocity, iceberg vertical profile, offset, added mass coefficient on peak force. A change in added mass coefficient from 0.5 to 2.5 caused a $50 \%$ increase in peak force and collision duration for a central impact. Sensitivity analysis performed by Johnson and Nevel [17] revealed the interaction geometry as the most significant factor. Duthinh [18] found impact velocity and indentor shape to be most significant factors. Ice strength was also found important factor especially for large contact areas. Gao et al. [19] investigated iceberg geometry shape in ship-iceberg collision process through sensitivity analysis. The authors also examined the effects of impact velocity taking as random values and entrapped water effect by changing added mass coefficient during interaction.

In this paper a simplified mathematical model is developed to estimate iceberg impact load for head on impact. The single degree of freedom model is based on energy conservation and energy dissipation is assumed through crushing only. Then sensitivity analysis is performed to identify effects of different impact velocity and added mass in iceberg impact load estimation and subsequent results are presented. Statistical design of experiment methodology is also used to identify significant factors and their contribution on the impact load.

\section{Mathematical Model of Iceberg Impact Load}

Energy based mathematical models have been used by several researchers. Cammaert and Tsinker [20] utilized an energy based model to calculate large ice floe and iceberg impact on structures. The model was based on kinetic energy dissipation through crushing of ice feature. Johnson and Nevel [17] developed energy based mathematical model to estimate structure design load for ice impact. The design loads were estimated using Monte Carlo distribution assuming constant ice strength, rigid structure and head on impact. Bass et al. [16] developed a three degree of freedom math model in horizontal plane for iceberg impact with gravity based structure. The model included both eccentric (kinetic energy absorbed by ice crushing) and oblique (kinetic energy absorbed by ice crushing and induced yaw motion) impacts of icebergs with variation in underwater profile. Gershunov [13] developed analytical equations for ice kinetic energy, ice indentation and global ice load developing during ice feature collision with structure using energy balance criteria.

In order to perform the sensitivity analysis, a simplified mathematical model 
developed in this paper is based on energy conservation during impact. This is a single degree of freedom iceberg impact model which considers the initial kinetic energy of iceberg is dissipated by ice crushing only. Although the model is simple and conservative in nature, it will still serve the main focus of the paper which is to conduct the sensitivity analysis of the parameters of interest. The model is also used to populate the response data in the design of experiment analysis.

In the present analysis, the following assumptions are made:

- Only central head on impact is considered.

- The structure is rigid and immovable and there is no deformation of the structure during the impact.

- The total kinetic energy of the iceberg/bergy bit prior to impact is absorbed by crushing ice until comes to a complete stop (velocity becomes zero).

- No elastic deformation is considered for the iceberg.

Let us consider an ice feature (iceberg/bergy bit) with a mass $M$ and initial impact velocity of $V_{i}$. The surge displacement, velocity and acceleration of the ice feature are $x, \dot{x}$ and $\ddot{x}$ respectively.

$$
\text { Initial kinetic energy }=\frac{1}{2}\left(1+C_{m}\right) m V_{i}^{2},
$$

where $C_{m}$ is the added mass coefficient.

Penetration depth during impact goes from $x=0$ to $x=x_{m}$ when $\dot{x}$ becomes zero.

$$
\text { Force during impact, } F=p A
$$

where $p$ is the ice crushing strength considered constant in the present analysis.

$$
\text { Work done due to crushing of ice }=\int_{0}^{x_{m}} F \mathrm{~d} x
$$

A Matlab code has been developed and $\ddot{x}$ is solved using ode 45 for each time step. Simulation is stopped when the velocity $\dot{x}$ becomes zero. The penetration depth, $x$ calculated at each time step is multiplied by height to calculate the area of interaction. This area is then multiplied by constant ice crushing pressure to estimate the load at each time step. The maximum load is the final value of force in each simulation and time of exposure is the total time in each simulation until velocity becomes zero.

\section{Input and Output Parameters}

A vertical sided structure of $200 \mathrm{~m}$ width is considered and the iceberg/bergy bit shape is taken as triangular cylinder (Figure 1).

The angle of the cone was taken as 60 degree and penetration width can be calculated as:

$$
2 * x * \tan \left(30^{\circ}\right)
$$

The other dimensions and properties are taken as follows (Table 1): 


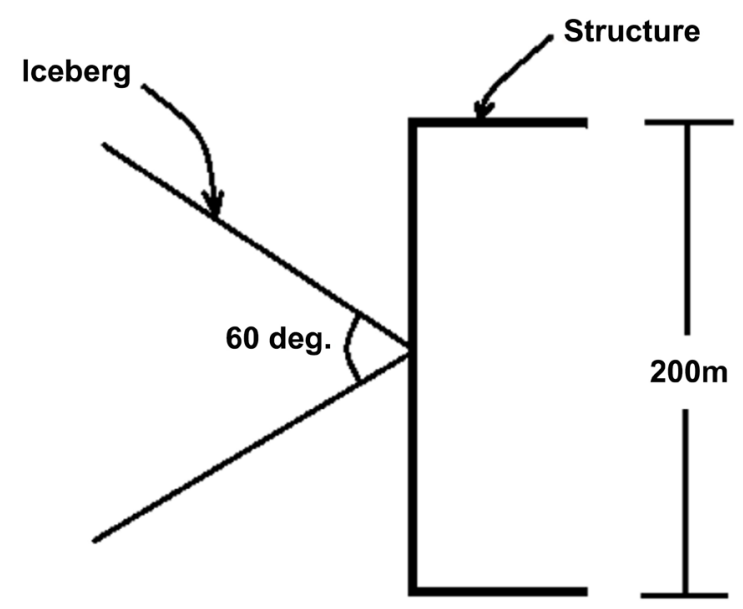

Figure 1. Iceberg-structure interaction (Top View).

Table 1. Size characteristics of iceberg/bergy bit [21].

\begin{tabular}{ccc}
\hline Type & Height $(\mathrm{m})$ & Approximate mass (tonnes) \\
\hline Bergy bit & 2 & 3000 \\
Iceberg & 50 & 300,000
\end{tabular}

Two ice crushing strengths ( 1 and $3 \mathrm{MPa}$ ) are considered. Three uniformly distributed added mass coefficients with ranges of $0.1-0.9,0.9-1.7$ and $1.7-2.5$ are considered. Similarly three uniformly distributed impact velocities with different ranges are considered which differed for iceberg and bergy bit since bergy bits travel faster than icebergs. The ranges of impact velocities are as follow (Table 2).

During the Monte Carlo simulation, when investigating effect of impact velocity the distribution of added mass coefficients are kept constant in a range of 0.5 - 1.5. Similarly when investigating effect of added mass coefficient, the distribution of impact velocity are kept constant in a range of 0.5 - 1 knots for iceberg and 2 - 3 knots for bergy bit.

\section{Sensitivity Analysis Using Monte-Carlo Simulation}

This section presents the results of sensitivity analysis performed for both iceberg and bergy bit. Added mass and impact velocity were the parameters of interest. Since iceberg impact is a rare event, 100,000 samples were taken during Monte-Carlo simulation to find probability of exceedence in $10^{-5}$ (100,000 years).

\subsection{Effect of Added Mass}

Added mass effect is analyzed by changing added mass coefficients. Figures 2-5 show the results for both iceberg and bergy bit at different ice strength and Table 3 summarizes the results of maximum load at $10^{-5}$ probability of exceedence.

The results demonstrate significant influence of added mass on maximum 
Table 2. Range of impact velocities for different ice features.

\begin{tabular}{cc}
\hline Type & Range of impact velocity (knots) \\
\hline Iceberg & $0.2-0.8,0.8-1.4$ and $1.4-2$ \\
Bergy bit & $1-2,2-3$, and $3-4$ \\
\hline
\end{tabular}

Table 3. Summary results—added mass effects on maximum load.

\begin{tabular}{cccccc}
\hline Type & $\begin{array}{c}\text { Range of added } \\
\text { mass coefficient }\end{array}$ & $\begin{array}{c}\text { Maximum load } \\
\text { (using ice strength } \\
\text { =1 MPa), MN }\end{array}$ & $\begin{array}{c}\text { Difference } \\
\text { (in \%) }\end{array}$ & $\begin{array}{c}\text { Maximum load } \\
\text { (using ice strength } \\
=3 \mathrm{MPa} \text { ), MN }\end{array}$ & $\begin{array}{c}\text { Difference } \\
\text { (in \%) }\end{array}$ \\
\hline Iceberg & $0.1-0.9$ & 93.1 & 0 & 161.3 & 0 \\
Iceberg & $0.9-1.7$ & 111.1 & 19.3 & 192.3 & 19.2 \\
Iceberg & $1.7-2.5$ & 126.5 & 35.9 & 218.9 & 35.7 \\
Bergy bit & $0.1-0.9$ & 5.6 & 0 & 9.7 & 0 \\
Bergy bit & $0.9-1.7$ & 6.7 & 19.6 & 11.6 & 19.6 \\
Bergy bit & $1.7-2.5$ & 7.6 & 35.7 & 13.2 & 36.1 \\
\hline
\end{tabular}

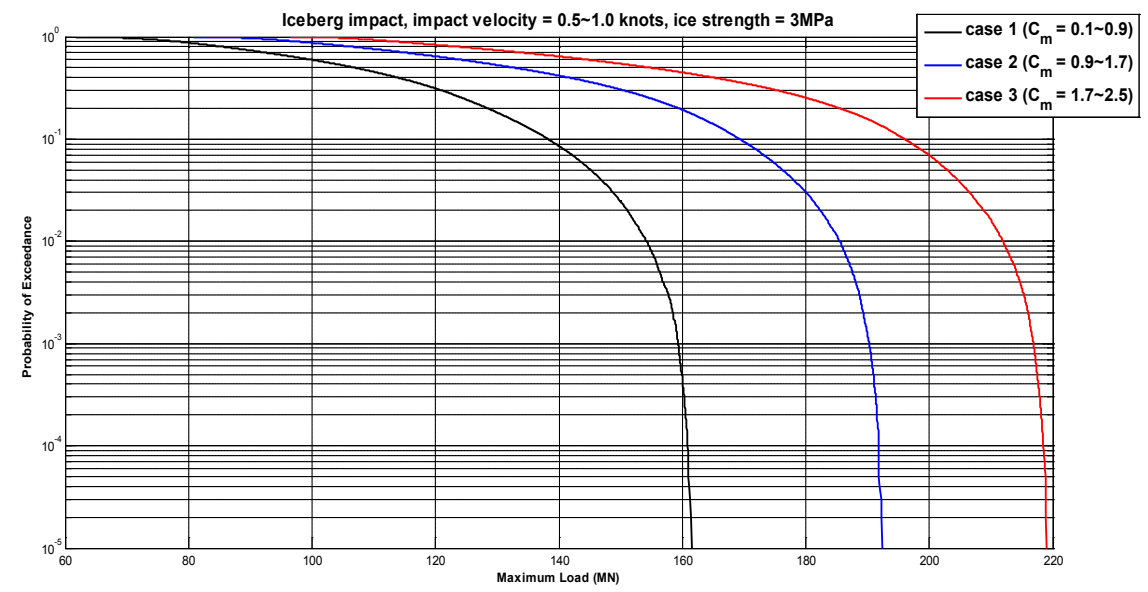

Figure 2. Effect of added mass on maximum load for iceberg with maximum ice crushing strength.

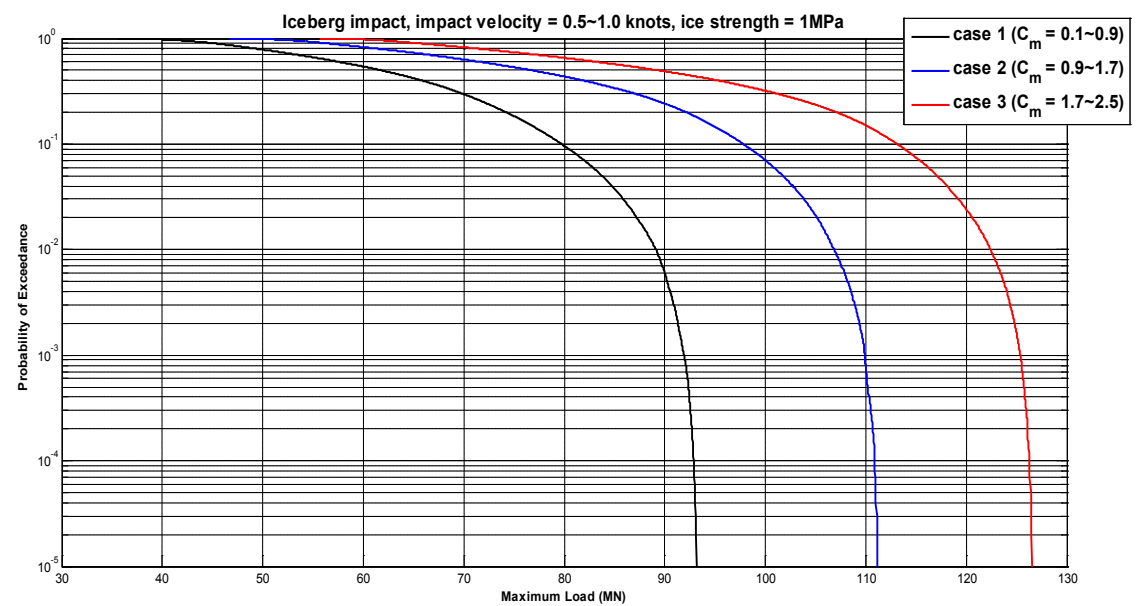

Figure 3. Effect of added mass on maximum load for iceberg with minimum ice crushing strength. 


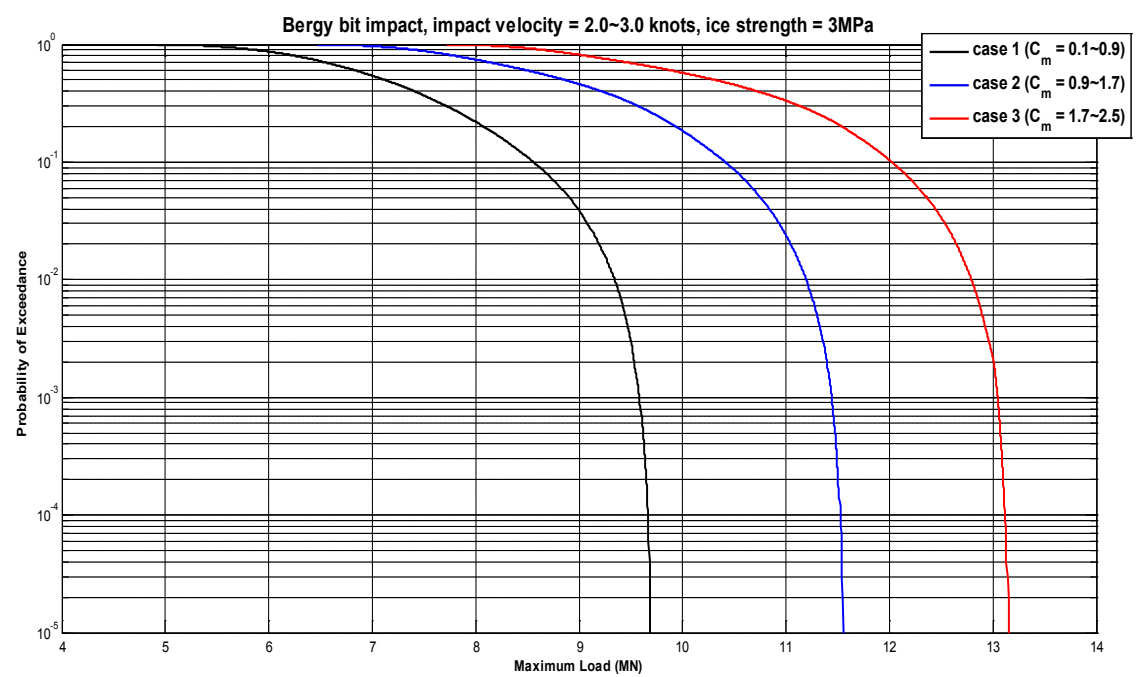

Figure 4. Effect of added mass on maximum load for bergy bit with maximum ice crushing strength.

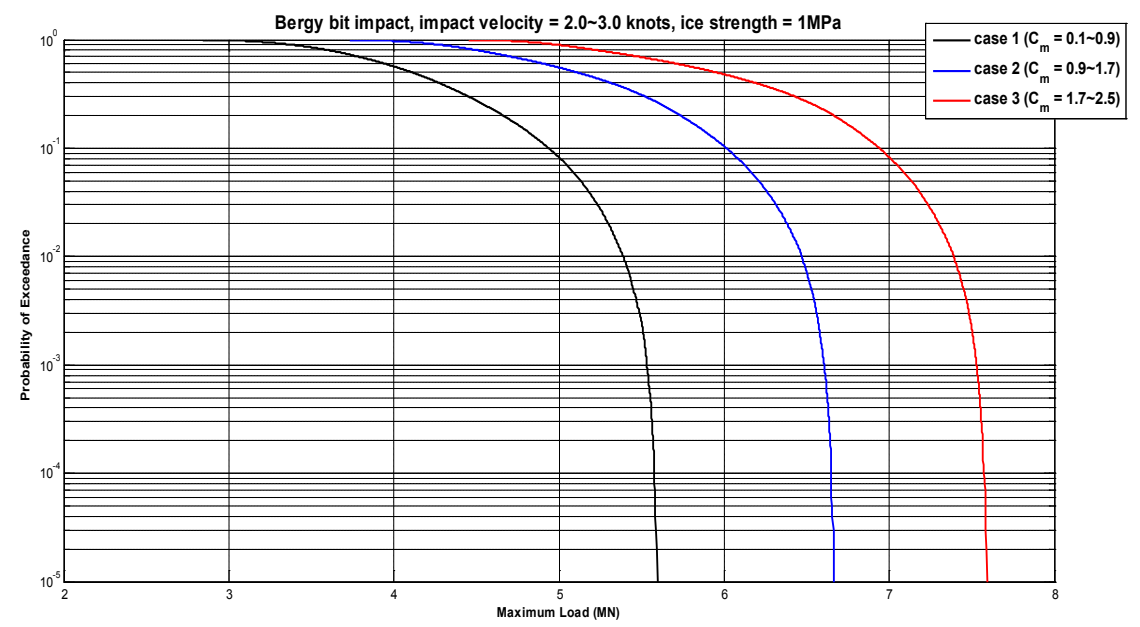

Figure 5. Effect of added mass on maximum load for bergy with minimum ice crushing strength.

load during iceberg and bergy bit impact. The increased range of added mass coefficient from $0.1-0.9$ to $0.9-1.7$ increased the maximum load by almost $19 \%$ and when the range is $1.7-2.5$, which is probably the expected range just before impact increases the maximum load by almost $35 \%$ for both iceberg and bergy bit. So using a generic added mass coefficient of 0.5 may result in significant underestimation in iceberg/bergy bit impact load.

\subsection{Effect of Impact Velocity}

Three different ranges of impact velocities were used for each iceberg and bergy bit. The ranges reflect the expected slow drift of iceberg compared to the bergy bit. Figures 6-9 show the results for both iceberg and bergy bit at different ice strength and Table 4 summarizes the results of maximum load at $10^{-5}$ probability of exceedence. 


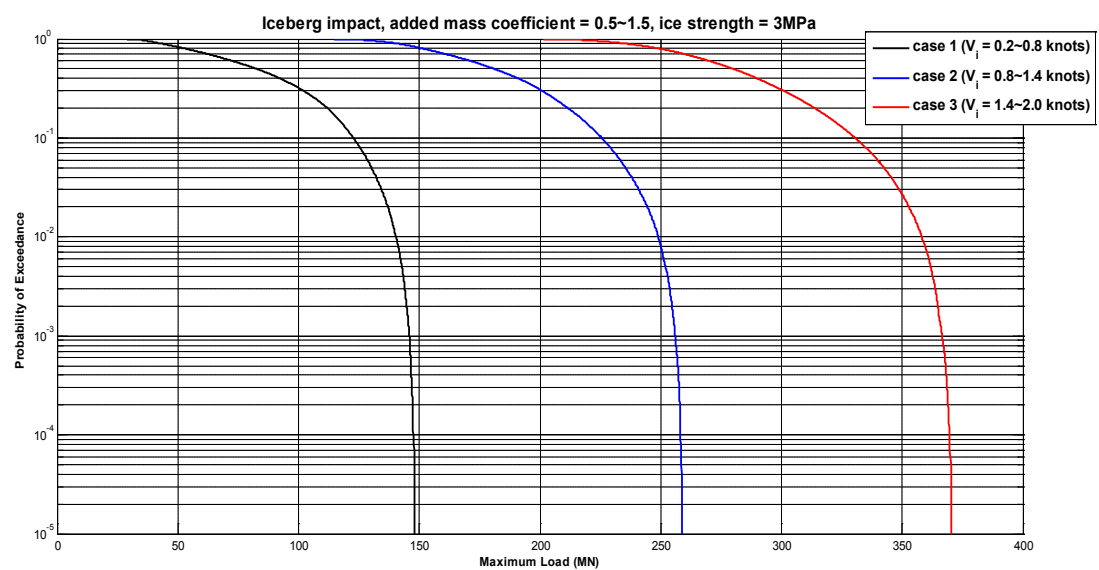

Figure 6. Effect of impact velocity on maximum load for iceberg with maximum ice crushing strength.

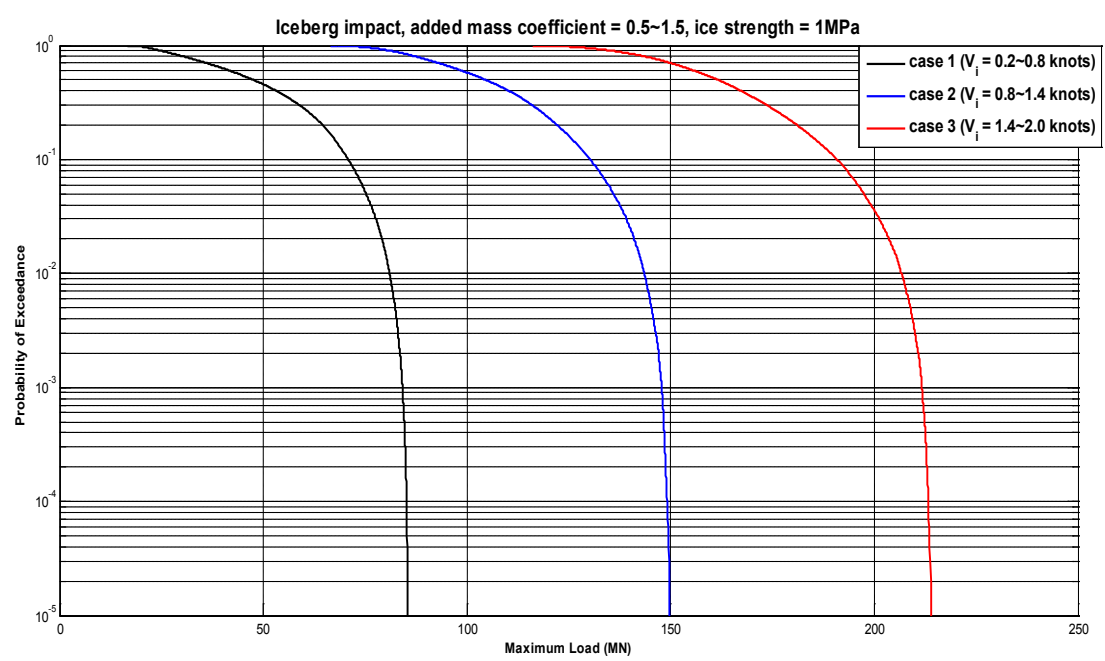

Figure 7. Effect of impact velocity on maximum load for iceberg with minimum ice crushing strength.

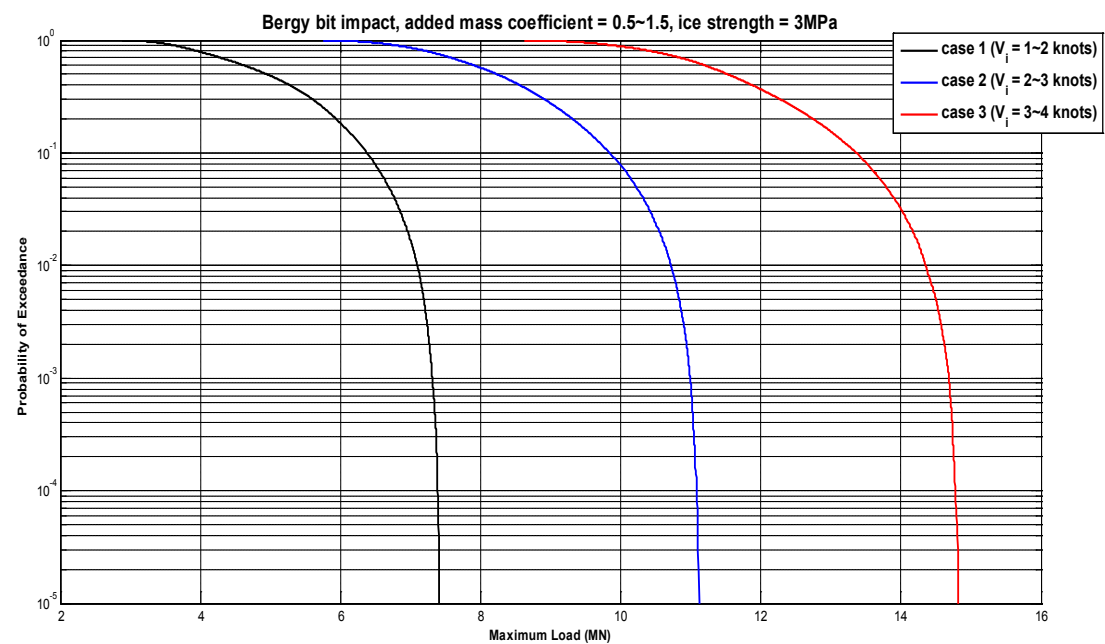

Figure 8. Effect of impact velocity on maximum load for bergy bit with maximum ice crushing strength. 


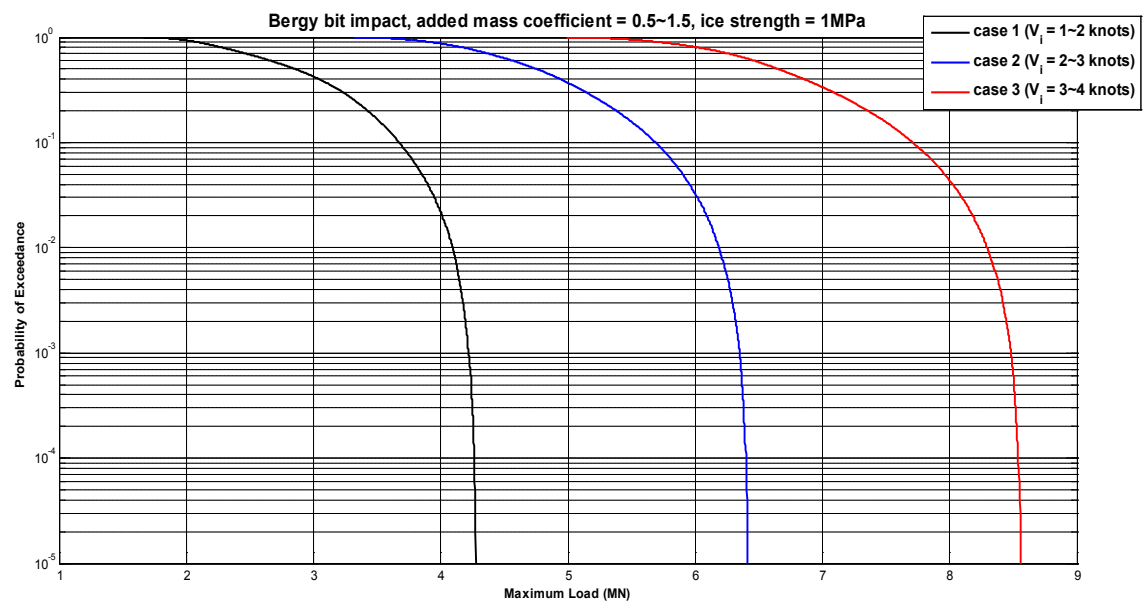

Figure 9. Effect of impact velocity on maximum load for bergy with minimum ice crushing strength.

Table 4. Summary results-impact velocity effects on maximum load.

\begin{tabular}{cccccc}
\hline Type & $\begin{array}{c}\text { Range of impact } \\
\text { velocity (knots) }\end{array}$ & $\begin{array}{c}\text { Maximum load } \\
\text { (using ice strength } \\
=1 \mathrm{MPa} \text { ), MN }\end{array}$ & $\begin{array}{c}\text { Difference } \\
\text { (in \%) }\end{array}$ & $\begin{array}{c}\text { Maximum load } \\
\text { (using ice strength } \\
\text { = 3 MPa), MN }\end{array}$ & $\begin{array}{c}\text { Difference } \\
\text { (in \%) }\end{array}$ \\
\hline Iceberg & $0.2-0.8$ & 85.4 & 0 & 148 & 0 \\
Iceberg & $0.8-1.4$ & 149.7 & 75.3 & 258.7 & 74.8 \\
Iceberg & $1.4-2.0$ & 213.9 & 150.5 & 370.4 & 150.27 \\
Bergy bit & $1.0-2.0$ & 4.3 & 0 & 7.4 & 0 \\
Bergy bit & $2.0-3.0$ & 6.4 & 48.8 & 11.1 & 50 \\
Bergy bit & $3.0-4.0$ & 8.6 & 100 & 14.8 & 100 \\
\hline
\end{tabular}

The results show quite significant effect of impact velocity on impact load estimation for iceberg and bergy bit. If someone calculates the impact load for iceberg taking a range of $1.4-2.0$ knots which may be the open water drift velocity, the estimated impact load may be overestimated by almost $150 \%$ since the velocity prior to impact may reduce to a range of $0.2-0.8$ knots. The effects are a bit less for bergy bit since their speed ranges are higher than iceberg. So ignoring hydrodynamic interaction prior to impact which causes significant reduction in impact velocity may result in overestimation of impact load and this effect is more for slower speeds.

\subsection{Realistic Impact Scenario}

It is evident from various model tests and other literature that impact velocity reduces just prior to impact [9], whereas added mass sharply increases prior to impact [14]. Thus in orders to simulate more realistic impact scenarios, two cases were considered-one for iceberg and one for bergy bit by taking lowest distribution of impact velocity and highest distribution of added mass. Maximum ice crushing strength was used for both simulations. 
Figure 10 and Figure 11 show the results of realistic impact scenarios and the maximum load is tabulated in Table 5. The added mass and impact velocity distributions used in these cases are also shown in Table 5.

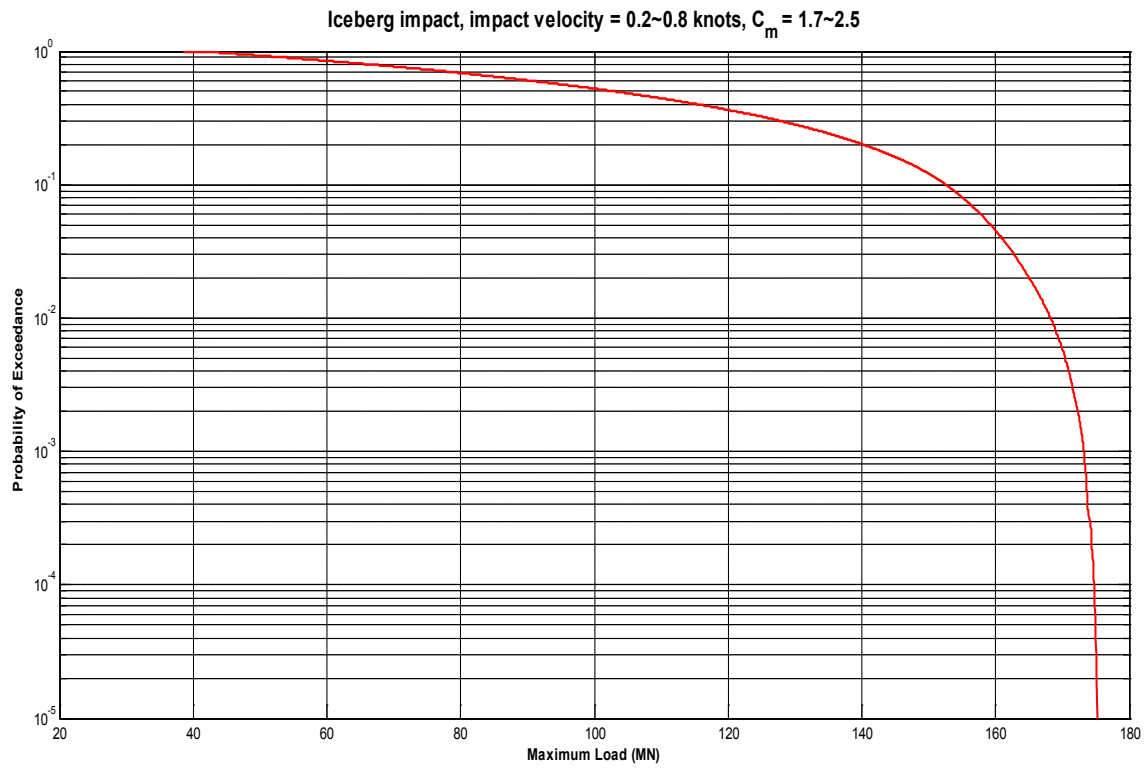

Figure 10. Realistic impact scenario for iceberg.

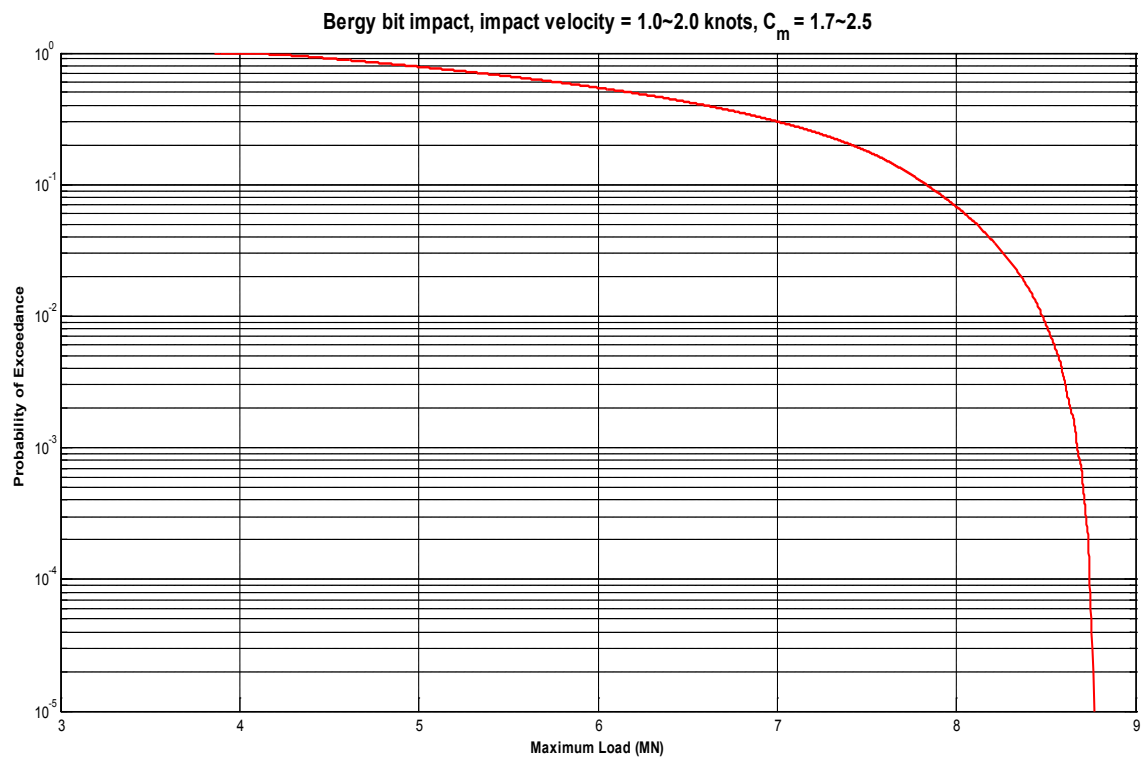

Figure 11. Realistic impact scenario for bergy bit.

Table 5. Two test cases to simulate realistic impact scenarios.

\begin{tabular}{cccc}
\hline Type & $\begin{array}{c}\text { Range of impact velocity } \\
\text { (knots) }\end{array}$ & $\begin{array}{c}\text { Range of added mass } \\
\text { coefficient }\end{array}$ & $\begin{array}{c}\text { Maximum load (using } \\
\text { ice strength }=3 \mathrm{MPa} \text { ), } \\
\text { MN }\end{array}$ \\
\hline Iceberg & $0.2-0.8$ & $1.7-2.5$ & 175.1 \\
Bergy bit & $1-2$ & $1.7-2.5$ & 8.8 \\
\hline
\end{tabular}


The results show significant combined effects of added mass and impact velocity in impact load estimation. Estimated values of maximum load by considering reduction in impact velocity and increase in added mass fall in lower range of estimated maximum values for other combinations checked previously.

\section{Design of Experiment (DOE) Methodology}

Design of Experiments or DOE is the systematic application of statistics to experimentation. It allows the development of a mathematical model that predicts how input variables interact to create output variables or responses in a process or system. DOE methods are also useful as a strategy for building mechanistic models, and they have the additional advantage that no complicated calculations are needed to analyze the data produced from the designed experiment [22]. By using DOE, one can learn about the process being investigated; screen important factors; determine whether factors interact; build a mathematical model for prediction; and optimize the response(s), if required. There are a wide variety of experimental designs available for both physical and computer experiments and their details can be found in many excellent texts such as [22] [23] [24] [25], and [26]. Some recent application of DOE methods in ocean engineering can be found in [27] [28] [29] and [30] among others.

\subsection{Choice of Factors, Response and Design}

To analyze the present problem, the case of bergy bit impact is considered and the following factors with their ranges and the response is chosen (Table 6). The 2-level full/fractional factorial design is often suitable for determining the significance of control parameters and screening out insignificant ones. This is based on the assumption of linear effect of the control parameters on the response function. A full factorial design (FFD) was used to carry out the DOE based analysis to account for all possible interactions between the control parameters. With four factors, the two-level full factorial design $\left(2^{4}\right)$ requires a combination of 16 experimental runs or calculation points. With one repeat for each test point, the DOE model will involve 32 design points.

\subsection{Results and Discussion}

\subsubsection{Diagnostic Plots and ANOVA}

Figure 12 shows couple of standard diagnostic plots and Table 7 shows the

Table 6. Factors and response.

\begin{tabular}{cccccc}
\hline Factor & Name & Unit & Type & Minimum & Maximum \\
\hline A & Mass & tonne & Numeric & 2500.00 & 3500.00 \\
B & Added mass coeff & - & Numeric & 0.5000 & 1.50 \\
C & Velocity & knot & Numeric & 0.5000 & 1.0000 \\
D & Ice strength & $\mathrm{MPa}$ & Numeric & 1.0000 & 3.00 \\
\hline
\end{tabular}

Response: Maximum Load (MN). 
Table 7. ANOVA table for selected model.

(a)

\begin{tabular}{ccccccc}
\hline Source & Sum of Squares & df & Mean Square & F-value & p-value & \% Contribution \\
\hline Model & 6.26 & 10 & 0.6260 & 32466.73 & $<0.0001$ & significant \\
A-Mass & 0.2021 & 1 & 0.2021 & 10482.14 & $<0.0001$ & 3.228 \\
B-Added mass coeff & 0.4651 & 1 & 0.4651 & 24120.75 & $<0.0001$ & 7.429 \\
C-Velocity & 3.37 & 1 & 3.37 & $1.746 \mathrm{E}+05$ & $<0.0001$ & 33.783 \\
D-Ice strength & 2.13 & 1 & 2.13 & $1.105 \mathrm{E}+05$ & $<0.0001$ & 0.0131 \\
AB & 0.0008 & 1 & 0.0008 & 42.71 & $<0.0001$ & 0.095 \\
AC & 0.0059 & 1 & 0.0059 & 308.21 & $<0.0001$ & 0.0601 \\
AD & 0.0038 & 1 & 0.0038 & 195.18 & $<0.0001$ & 0.219 \\
BC & 0.0137 & 1 & 0.0137 & 710.17 & $<0.0001$ & 0.138 \\
BD & 0.0087 & 1 & 0.0087 & 449.27 & $<0.0001$ & 1.001 \\
CD & 0.0627 & 1 & 0.0627 & 3251.86 & $<0.0001$ & \\
Residual & 0.0004 & 21 & 0.0000 & & & \\
Lack of Fit & 0.0004 & 5 & 0.0001 & & & \\
Pure Error & 0.0000 & 16 & 0.0000 & & & \\
Cor Total & 6.26 & 31 & & & \\
& & & & \\
\end{tabular}

(b)

\begin{tabular}{cccc}
\hline Std. Dev. & 0.0044 & $\mathbf{R}^{\mathbf{2}}$ & 0.9999 \\
\hline Mean & 1.89 & Adjusted R $^{\mathbf{2}}$ & 0.9999 \\
C.V. \% & 0.2323 & Predicted $\mathbf{R}^{2}$ & 0.9998 \\
& & Adeq Precision & 607.8231 \\
\hline
\end{tabular}
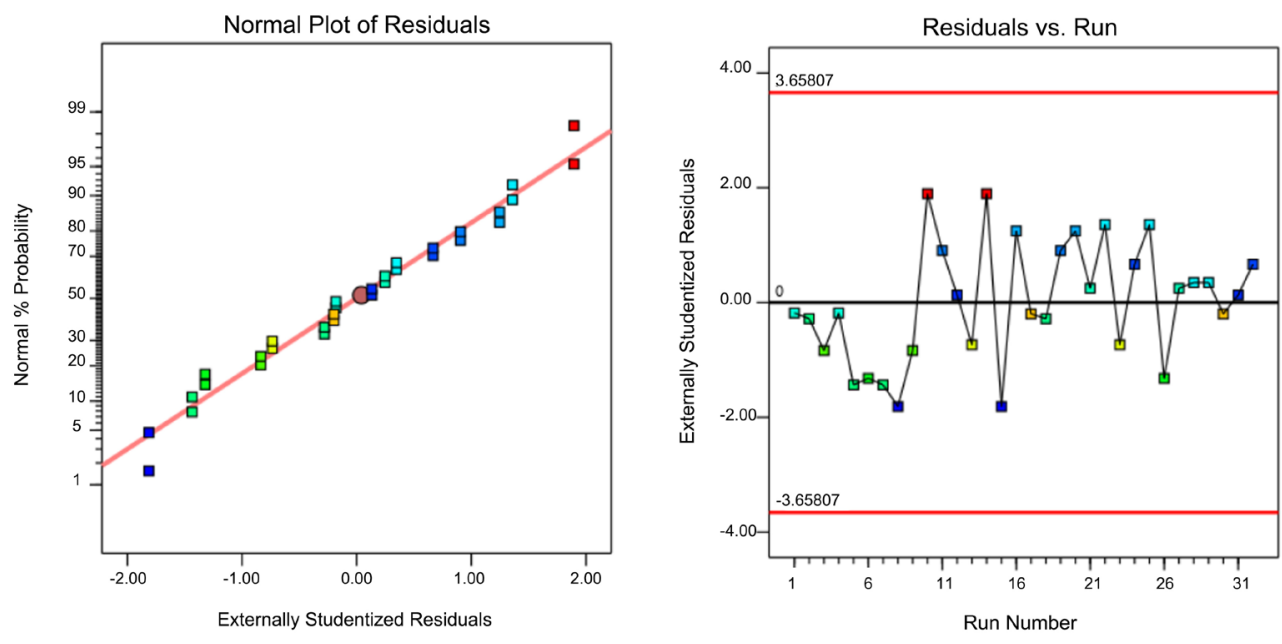

Figure 12. Diagnostic plots of the selected model.

ANOVA table for the selected model. The normal plot of residuals (left) show the residuals follow a straight line indicating that residuals follow normal distri- 
bution. The residuals vs. run plot (right) show random scatter indicating that no unaccounted time related variable are influencing results. The statistics of ANOVA table shows that the selected model is statistically significant. The percentage contribution of the significant factors are also shown in the ANOVA table.

\subsubsection{Sensitivity of Significant Factors}

Figure 13 and Figure 14 show the half normal plot and Pareto chart both of which clearly identifies the significant factors in the present model. These figures clearly indicate that impact velocity is the most significant factor contributing to the maximum impact load. It is interesting to see that ice crushing strength is the $2^{\text {nd }}$ most important factor which was not analysed during Monte-Carlo simulation in the last section. Added mass coefficient and mass of the berg turn out to be the $3^{\text {rd }}$ and $4^{\text {th }}$ important factors. It is also to be noted that the interaction effects don't have significant contribution in the present 2 FI DOE model.

\subsubsection{Mathematical Model}

In order to develop the 2-FI statistical model, a square root transformation was used. The developed DOE model of the response is only valid within the ranges of the factors. The resulting model is shown in Equation (4) and Figure 15 shows the actual and predicted values of the response.

Sqrt $($ Max Load $)=0.575333+1.35107 \mathrm{e}-05 \times$ Mass $+-0.00968987 \times$ Added mass coeff $+0.450827 \times$ Velocity $+0.0272424 \times$ Ice strength $+2.0291 \mathrm{e}-05 \times$ Mass $\times$ Added mass coeff $+0.000109019 \times$ Mass $\times$ Velocity $+2.16888 \mathrm{e}-05 \times$ Mass $\times$ Ice strength $+0.165486 \times$ Added mass coeff $\times$ Velocity $+0.0329059 \times$ Added mass coeff $\times$ Ice strength $+0.177058 \times$ Velocity $\times$ Ice strength
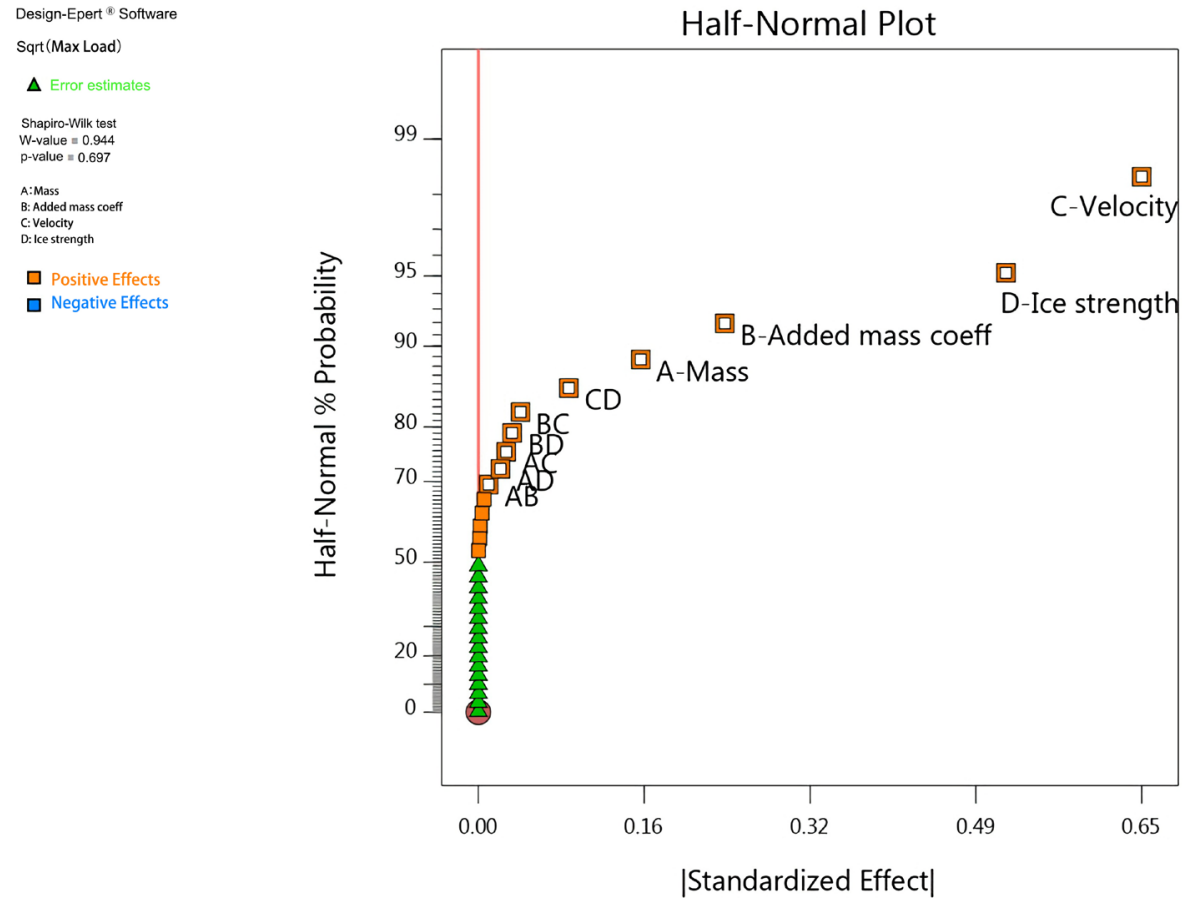

Figure 13. Half-normal plot of selected 2FI model showing significant factors. 
Design-Epert ${ }^{\infty}$ Software

Sqrt(Max Load)

A:Mass

B: Added mass coeff
C: Velocity
D: lee strength

口 Positive Effects

$\square$ Negative Effects

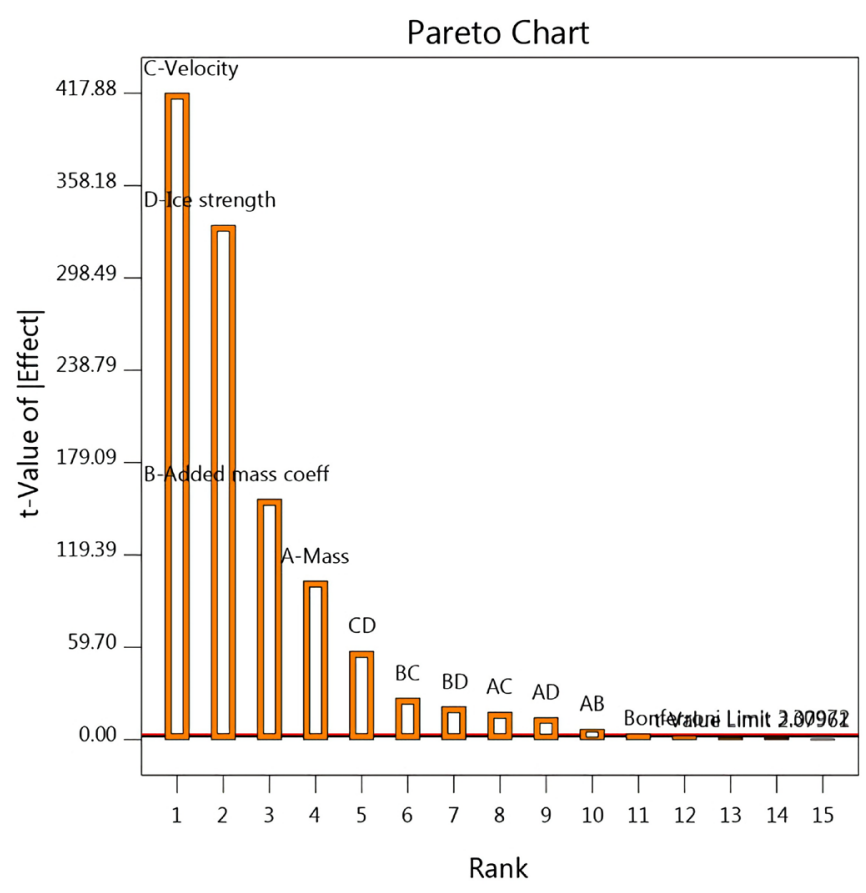

Figure 14. Pareto chart showing significant factors in the selected model.

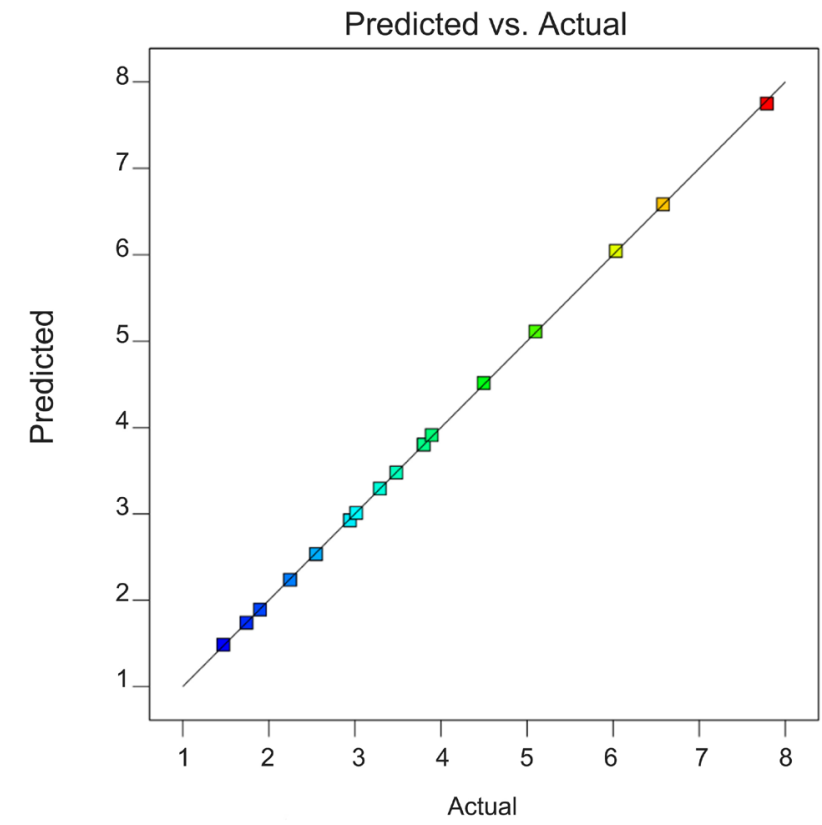

Figure 15. Predicted vs actual plot for the 2FI DOE model.

\subsubsection{Parametric and Interaction Effects}

Various plots are available to see the effects of the factors on the response. Results also show various interaction effects on the response. Figure 16 shows the effect of impact velocity, ice strength and added mass coefficient change on the maximum impact load. This again demonstrates that the impact velocity is the most significant factor in the present model. Figure 17 shows the interaction effects of velocity and added mass coefficient (left) and ice strength and velocity 

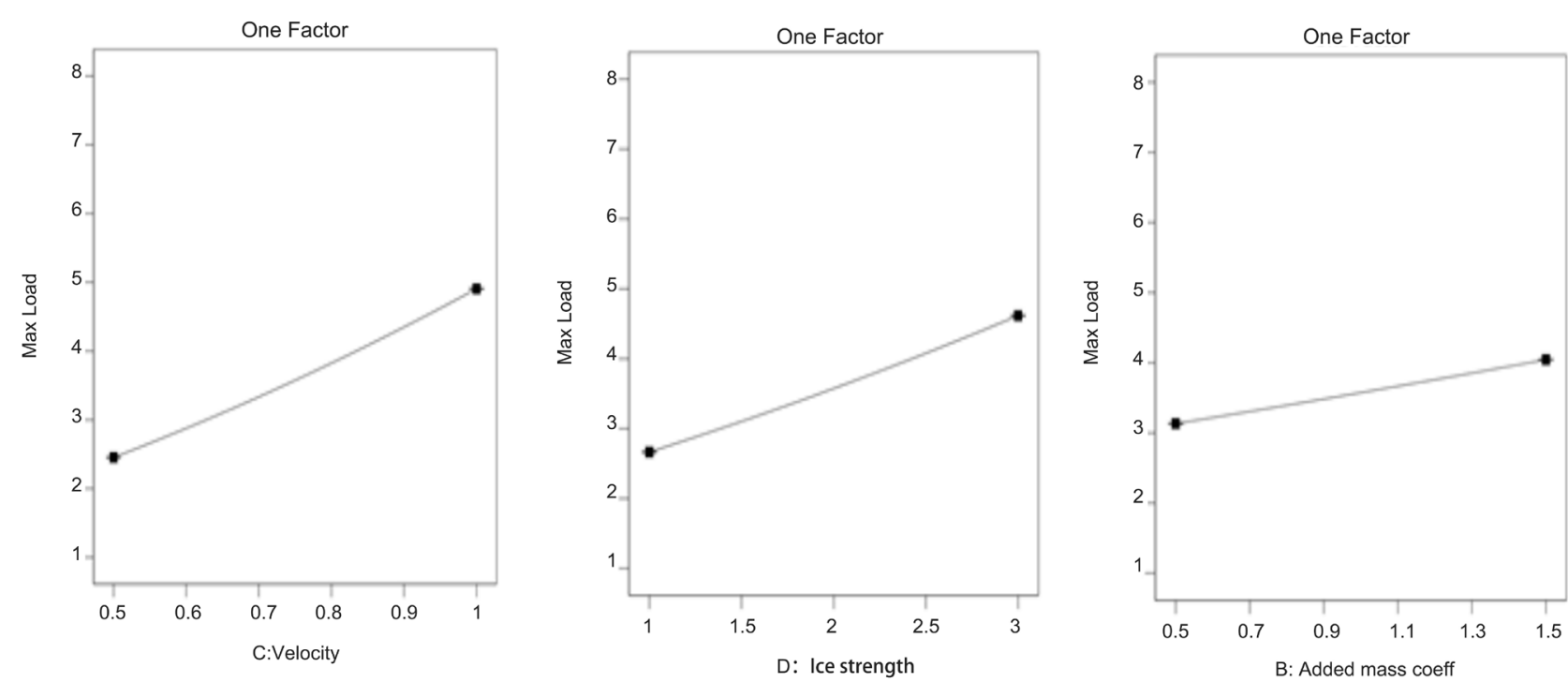

Figure 16. One factor effects on the response.
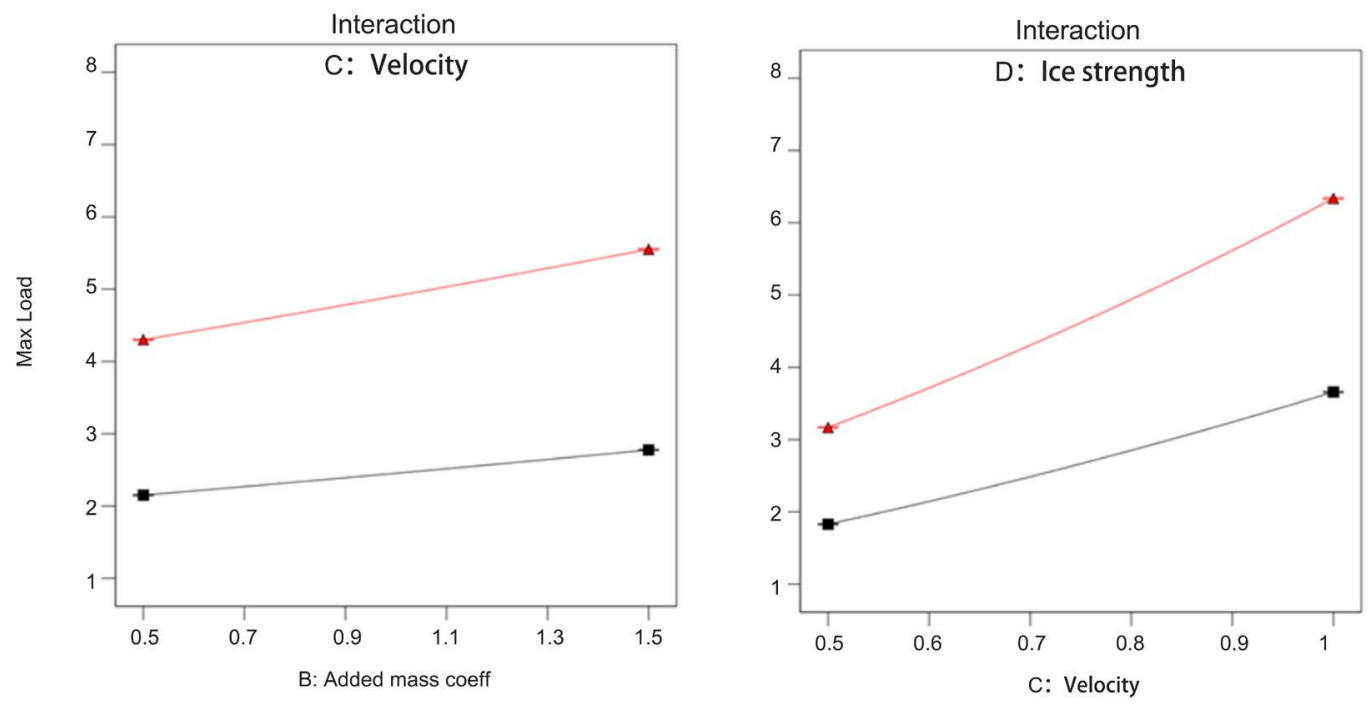

Figure 17. Interaction effects on the response.

(right) on the maximum impact load. The red line indicates the high values and the black line indicates the low values. Although interaction terms are not significant in the present model, these plots help to identify the effect of one factor depends on the level of another factor. For example, it can be interpreted from Figure 17 that the effect of added mass coefficient on maximum impact load is more pronounced when the impact velocity is higher. Also the increasing trend of maximum impact load due to the increase in impact velocity is steeper when the ice crushing strength is maximum.

\section{Future Research}

Since ice crushing strength is identified as the $2^{\text {nd }}$ most important factor in the DOE analysis, it will be interesting to see the sensitivity of ice strength using 
Monte-Carlo simulation. The next logical approach will be to use improved mathematical model including rotation of the berg during impact and pressure-area model. Also more complicated interaction geometry can be added to mathematical model. Last but not least, duration of impact can also be considered as an output of analysis.

\section{Conclusions}

Iceberg/bergy bit impact load with ships and offshore structures is an important design consideration in ice prone regions like Grand Banks. Inaccurate estimation of impact load may result in overestimation in design load affecting the economy of the project. The usual practice is to consider mean open water drift velocity as impact velocity and added mass coefficient of 0.5 during estimation of iceberg/bergy bit impact load.

In this paper a simplified iceberg/bergy bit impact model has been developed based on limited energy method. The effects of added mass and impact velocity have been identified through sensitivity analysis using Monte-Carlo simulation. The results demonstrate significant effects of impact velocity and added mass on maximum impact load estimation which is more pronounced for impact velocity. The combined effects of these two factors are also simulated in two test cases where it shows relatively lower value of maximum impact load. The statistical design of experiment methodology is also used to identify significant factors and their interaction effects on the maximum impact load of a bergy bit. DOE analysis also signifies the effect of ice crushing strength besides impact load and added mass coefficient. It is evident from the present analysis that the hydrodynamic interaction prior to impact should be an important consideration which causes reduction in impact velocity and increase in added mass just prior to impact. Otherwise the estimation of maximum impact load will be significantly overestimated.

\section{Conflicts of Interest}

The authors declare no conflicts of interest regarding the publication of this paper.

\section{References}

[1] Duthinh, D., Klein, K., Regrettier, J., Guichard, A. and Engler, M. (1990) Full Scale Iceberg Impact: A Pilot Experiment in Antarctica. Proceedings of the 10 th International Symposium on Ice, Espoo, 890-901.

[2] Bruneau, S.E., Cammaert, A.B. and Croasdale, K.R. (1994) Field Tests for Iceberg Impact Loading. 12th International Symposium on Ice, Trondheim, 23-26 August 1994, Vol.1, 187-197.

[3] Ralph, F., McKenna, R., Crocker, G. and Croasdale, K. (2004) Pressure/Area Measurement from the Grappling Island Iceberg Impact Experiment. Proceedings IAHR Symposium on Ice, St. Petersburg, Vol. 2, 171-178.

[4] Salvalggio, M.A. and Rojansky, M. (1986) The Importance of Wave-Driven Icebergs 
Impacting an Offshore Structure. Offshore Technology Conference, Houston, 5-8 May 1986, OTC-5086-MS. https://doi.org/10.4043/5086-MS

[5] Isaacson, M. and McTaggart, K. (1990) Modelling of Iceberg Drift Motions near a Large Offshore Structure. Cold Regions Science and Technology, 19, 47-58. https://doi.org/10.1016/0165-232X(90)90017-Q

[6] Isaacson, M. and Cheung, K.F. (1988) Influence of Added Mass on Ice Impacts. Canadian Journal of Civil Engineering, 15, 698-708. https://doi.org/10.1139/188-090

[7] Colbourne, D.B., Smoes Re, A., Drodge, R. and Sullivan, M. (1998) Terra Nova FPSO Iceberg Impact Tests. IMD Report TR-1998-18 (Protected) to SOFEC Inc.

[8] Gagnon, R.E. (2004) Physical Model Experiments to Assess the Hydrodynamic Interaction between Floating Glacial Ice Masses and a Transiting Tanker. Journal of Offshore Mechanics and Arctic Engineering, 126, 297-309. https://doi.org/10.1115/1.1835986

[9] Sayeed, T., Colbourne, B., Peng, H., Colbourne, B. and Spencer, D. (2015) Experimental Investigation of Ice Mass Hydrodynamic Interaction with Offshore Structure in Close Proximity. Proceedings of the 34th International Conference on Ocean, Offshore and Arctic Engineering, St. John's, 31 May-5 June 2015, V007T06A048. https://doi.org/10.1115/OMAE2015-41394

[10] Cammaert, A.B., Wong, T.T. and Curtis, D.D. (1983) Impact of Icebergs on Offshore Gravity and Floating Platforms. Proceedings of the 7 th International Conference on Port and Ocean Engineering under Arctic Conditions, Helsinki, 5-9 April 1983, 519-536.

[11] Habib, K., Taylor, R., Jordaan, I. and Bruneau, S. (2014) Experimental Investigation of Compressive Failure of Truncated Conical Ice Specimens. Proceedings of $33 \mathrm{rd}$ International Conference on Ocean, Offshore and Arctic Engineering, San Francisco, 8-13 June 2014, OMAE2014-24184.

[12] Lever, J.H., Colbourne, B. and Mak, L. (1988) A Model Study of the Wave-Induced Motion of Small Icebergs and Bergy Bits. Journal of Offshore Mechanics and Arctic Engineering, 110, 101-107. https://doi.org/10.1115/1.3257115

[13] Gershunov, E.M. (1986) Collision of Large Floating Ice Feature with Massive Offshore Structure. ASCE Journal of the Waterway, Port, Coastal and Ocean Engineering, 112, 390-401. https://doi.org/10.1061/(ASCE)0733-950X(1986)112:3(390)

[14] Chwang, A.T. (2003) Interaction Hydrodynamics of Two Bodies. Proceedings of the 13th International Offshore and Polar Engineering Conference, Honolulu, 25-30 May 2003, 1-8.

[15] Cheung, K.F. (1987) Hydrodynamic Interactions between Ice Masses and Large Offshore Structures. Masters' Thesis, University of British Columbia, Vancouver.

[16] Bass, D., Gaskill, H. and Riggs, N. (1985) Analysis of Iceberg Impact with Gravity Base Structures at Hibernia. Proceedings of the 4th International Conference on Offshore Mechanics and Arctic Engineering, Dallas, Texas, 17-21 February 1985, Vol. 3, 255-259.

[17] Johnson, R.C. and Nevel, D.E. (1985) Ice Impact Structural Design Loads. Proceedings of the 8th International Conference on Port and Ocean Engineering under Arctic Condition, Narssarssuaq, 7-14 September 1985, 569-578.

[18] Duthinh, D. (1989) Parametric Study of Iceberg Impact Loads. Proceedings of the International Conference on Port and Ocean Engineering under Arctic Conditions, Lulea, 12-16 June 1989, 492-503.

[19] Gao, Y., Hu, Z. and Wang, J. (2014) Sensitivity Analysis for Iceberg Geometry 
Shape in Ship-Iceberg Collision in View of Different Material Models. Mathematical Problems in Engineering, 2014, Article ID: 414362.

https://doi.org/10.1155/2014/414362

[20] Cammaert, A.B. and Tsinker, G.P. (1981) Impact of Large Ice Floes and Icebergs on Marine Structures. Proceedings of the 6 th International Conference on Port and Ocean Engineering under Arctic Conditions, Quebec, 27-31 July 1981, 653-667.

[21] Arunachalam, V.M., Bobby, W., Muggeridge, D.B. and Stacey, R.A. (1985) A Review of the Interaction of Icebergs with Offshore Structures. Proceedings of 4 th International Conference on Behaviour of Offshore Structures, Delft, July 1985, 693-704.

[22] Montgomery, D.C. (2005) Design and Analysis of Experiments. 5th Edition, Wiley, New York.

[23] Myers, R.H. and Montgomery, D.C. (2002) Response Surface Methodology: Process and Product Optimization Using Designed Experiments. 2d Edition, Wiley, New York.

[24] Fang, K.T., Li, R. and Sudjianto, A. (2006) Design and Modeling for Computer Experiments. Chapman and Hall/CRC Press, London.

https://doi.org/10.1201/9781420034899

[25] Forrester, A., Sobester, A. and Keane, A. (2008) Engineering Design via Surrogate Modelling-A Practical Guide. John Wiley and Sons, Hoboken.

https://doi.org/10.1002/9780470770801

[26] Goos, P. and Jones, B. (2011) Optimal Design of Experiments: A Case Study Approach. John Wiley and Sons, Hoboken. https://doi.org/10.1002/9781119974017

[27] Hawkins, D. and Lye, L.M. (2006) Use of DOE Methodology for Investigating Conditions That Influence the Tension in Marine Risers for FPSO Ships. 1st International Structural Specialty Conference, Calgary, 23-26 May 2006, 1-10.

[28] Islam, M.F. and Lye, L. (2008) Combined Use of Dimensional Analysis and Modern Experimental Design Methodologies in Hydrodynamics Experiments. Ocean Engineering, 36, 237-247. https://doi.org/10.1016/j.oceaneng.2008.11.004

[29] Sayeed, T.M., Lye, L. and Peng, H. (2014) Response Surface Models for Analyzing Planing Hull Motions in a Vertical Plane. Proceedings of OMAE 2014, San Francisco, 8-13 June 2014, V01AT01A034. https://doi.org/10.1115/OMAE2014-23489

[30] Sayeed, T.M., Lye, L. and Peng, H. (2015) Response Surface Models for Analyzing Sinkage and Trim Effects on Planing Hull Motions in a Vertical Plane. Proceedings of OMAE 2015, St. John's, 31 May-5 June 2015, V001T01A005.

https://doi.org/10.1115/OMAE2015-41392 